Paper for Space Cryogenics Workshop, June 24-26, 2015, Phoenix, Arizona

\title{
Numerical Modeling of Self-Pressurization and Pressure Control by Thermodynamic Vent System in a Cryogenic Tank
}

\author{
By \\ Alok Majumdar, Juan Valenzuela, Andre LeClair \\ NASA/Marshall Space Flight Center \\ $\&$ \\ Jeff Moder \\ NASA/Glenn Research Center
}

\begin{abstract}
This paper presents a numerical model of a system-level test bed - the multipurpose hydrogen test bed (MHTB) using Generalized Fluid System Simulation Program (GFSSP). MHTB is representative in size and shape of a fully integrated space transportation vehicle liquid hydrogen $\left(\mathrm{LH}_{2}\right)$ propellant tank and was tested at Marshall Space Flight Center (MSFC) to generate data for cryogenic storage. GFSSP is a finite volume based network flow analysis software developed at MSFC and used for thermo-fluid analysis of propulsion systems. GFSSP has been used to model the self-pressurization and ullage pressure control by Thermodynamic Vent System (TVS). A TVS typically includes a Joule-Thompson (J-T) expansion device, a two-phase heat exchanger, and a mixing pump and spray to extract thermal energy from the tank without significant loss of liquid propellant. Two GFSSP models (Self-Pressurization \& TVS) were separately developed and tested and then integrated to simulate the entire system. Self-Pressurization model consists of multiple ullage nodes, propellant node and solid nodes; it computes the heat transfer through Multi-Layer Insulation blankets and calculates heat and mass transfer between ullage and liquid propellant and ullage and tank wall. TVS model calculates the flow through J-T valve, heat exchanger and spray and vent systems. Two models are integrated by exchanging data through User Subroutines of both models. The integrated models results have been compared with MHTB test data of 50\% fill level. Satisfactory comparison was observed between test and numerical predictions.
\end{abstract}




\section{Introduction}

Numerical modeling of Cryogenic Fluid Management (CFM) applications such as long term storage of cryogen in space is very important to meet technological challenges of future mission. Numerical modeling tools need to have the sufficient fidelity to answer critical design and operational issues and must be verified by comparing with test data. The purpose of this paper is to develop a system level model of self-pressurization of a cryogenic tank with multiple nodes and verify the numerical predictions by comparing with test data. The test data from Multi-purpose Hydrogen Test Bed (MHTB) ${ }^{1}$ was used to verify the numerical model developed with Generalized Fluid System Simulation Program $(\text { GFSSP })^{2}$.

MHTB (Figure 1) is also capable of accommodating various CFM concepts and research. The AL 50830 aluminum tank is cylindrical shape with a diameter of 10 feet, a height of 10 feet, and 2:1 elliptical domes. Its size allows for comparable comparison with a fullscale cryogenic tank. The tank is enclosed in aluminum shroud for uniform and controllable temperature distribution throughout the outer surface of the passive insulation system. The entire test article is placed inside a 20 feet diameter vacuum chamber to simulate deep space thermal conditions.
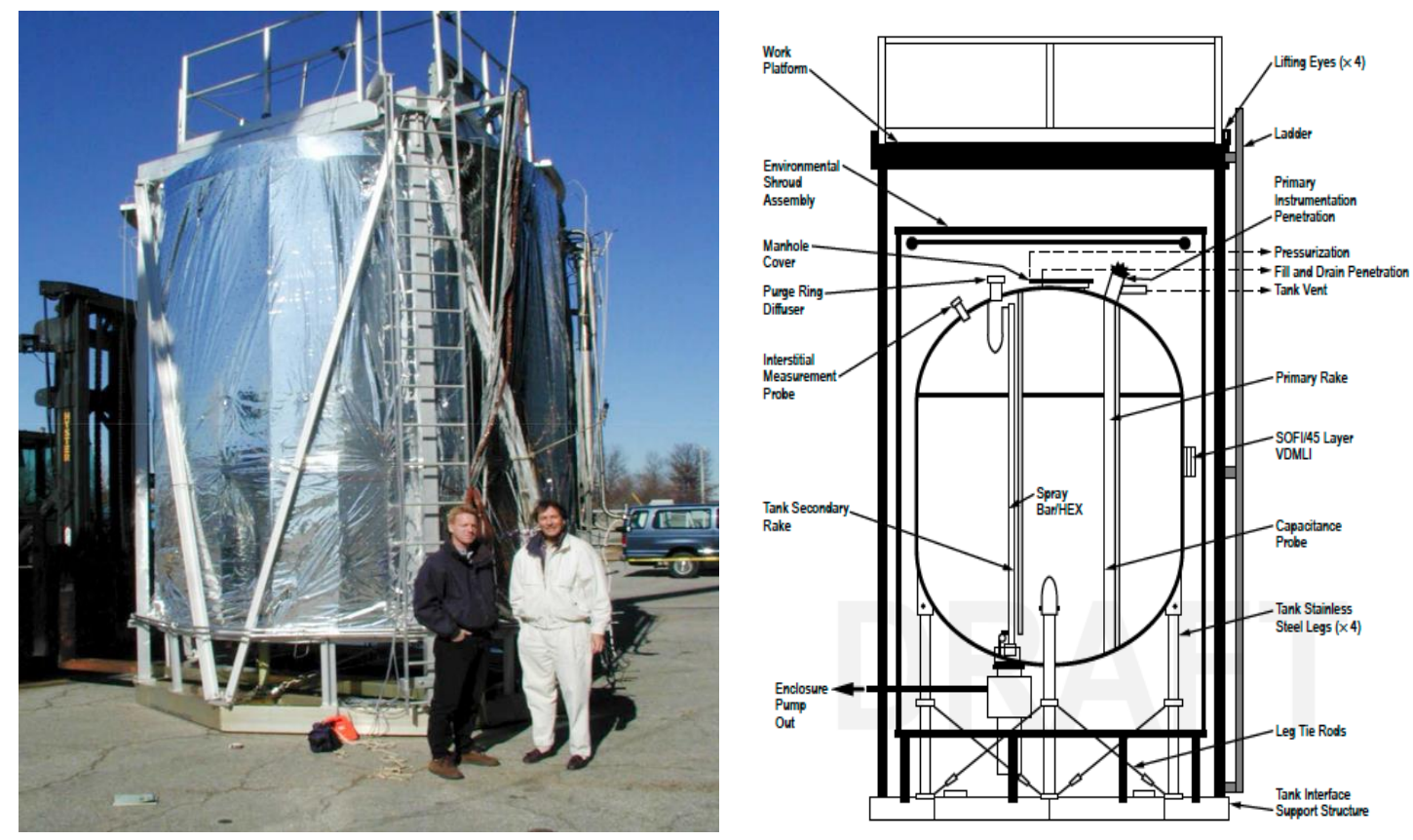

Figure 1. Multi-Purpose Hydrogen Test Bed

The passive thermal controls system of MHTB is comprised of a combination of Spray on Foam Insulation (SOFI) and Multi-Layer Insulation (MLI) system. The SOFI is a robotically sprayed-on application similar to that used on Space Shuttle External Tank foam application process. It has a nominal thickness of 0.56 in throughout the surface area 
of the tank. The MLI is comprised of a 45 layer variable density blanket placed over the SOFI. The blanket is comprised of 0.5 mil double aluminized Mylar as the radiation shield with B4A Dacron netting as the spacer layer between the Mylar. B4A Dacron bumper strips are used to create the variable density effect where there are fewer layers of MLI closer to the tank. In total there are three sub blankets of 10, 15 and 20 layers with a layer density of 8 Layers/cm, 12 Layers/cm, 16 Layers/cm respectively (Figure 2).

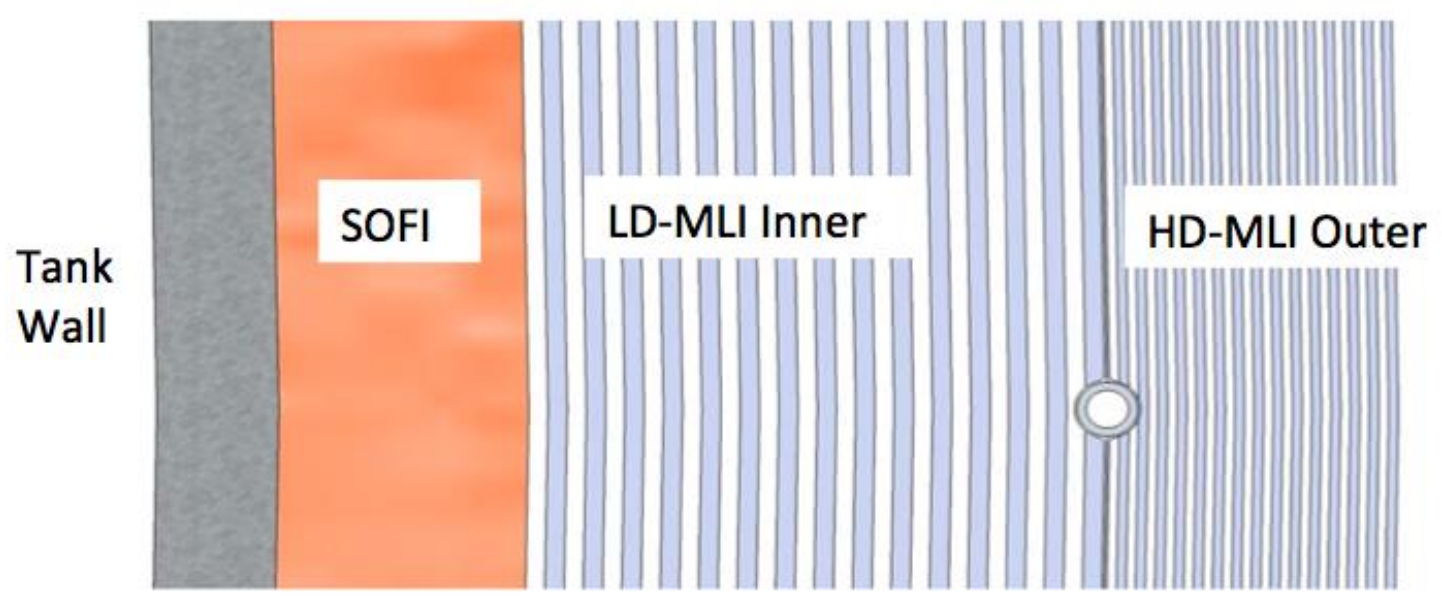

Figure 2. Cross Section of SOFI/variable density MLI configuration

The active pressure control system used in MHTB is a spray bar heat exchanger thermodynamic vent system (TVS) concept shown in Figure 3. It consists of a liquid hydrogen pump, Joule-Thompson device, concentric heat exchanger and longitudinal spray bar system.

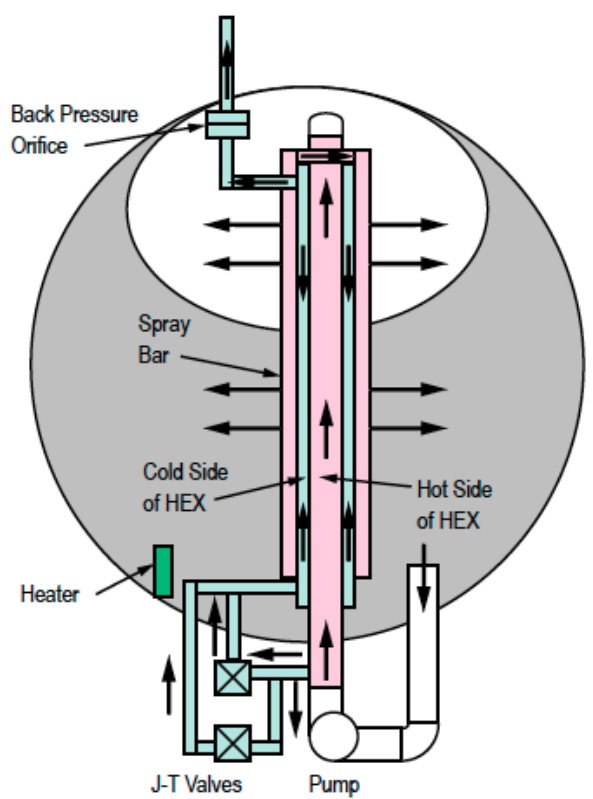

Figure 3. MHTB Spray Bar TVS 
During ullage mixing mode liquid is extracted form the bottom of the tank and fed to the longitudinal heat exchanger via the liquid pump. The fluid is then expelled radially throughout the spray bar to both the ullage and liquid. If passive thermal protection is sufficient then ullage mixing mode is enough to control tank ullage pressures with no propellant loss. When mixing alone cannot control tank pressure, during TVS operation a small portion of liquid is fed thru the Joule-Thompson device, expanding the liquid and thus lowering its pressure and temperature. The expanded fluid is then passed thru the heat exchanger to condition the mixing fluid portion of the heat exchanger loop and expelled thru a pressure control orifice to space ${ }^{3}$.

Previous attempts to model the MHTB during self-pressurization mode and TVS mode have been made in the past using single node for each component of the system. The Tank System Integrated Model (TankSIM) is a Fortan based program used to predict the behavior of cryogenic propellant under different conditions: self-pressurization, boil-off, ullage venting, mixing, and TVS system (Axial Jet and Spray bar), and two-phase heat exchange ${ }^{4}$. TankSIM consists of eight single nodes interacting with each other:

1. Ullage tank wall- dome section of tank

2. Ullage tank wall- cylinder section

3. Bulk Liquid tank wall

4. Bulk Liquid

5. Environment

6. Ullage-liquid Interface

7. Ullage

8. Tank Wall Liquid- liquid film on the ullage tank walls.

Although TankSIM can predict thermodynamic performance inside a cryogenic tank with reasonable accuracy, a multi node model is needed to attain better fidelity regarding tank stratification and ullage mixing in pressure control scenario and accurately depict heat load distribution around tank structures and tank surface area. Therefore a multi node ullage model was developed and compare with MHTB hydrogen test data.

This paper demonstrates the simulation of self-pressurization of a Liquid Hydrogen Tank and the pressure control with TVS using multi-node model. The simulation was performed with the general purpose flow network software, Generalized Fluid System Simulation Program (GFSSP) ${ }^{2}$ developed at Marshall Space Flight Center. A coupled model of selfpressurization and Thermodynamic Vent System was developed. The purpose of the GFSSP model is to simulate the initial self-pressurization when ullage pressure rises from the initial tank pressure to the upper bound pressure when the spray starts. Once the spray starts, a separate GFSSP model of TVS system was run in parallel with self-pressurization model to provide the necessary spray input such as flow rate and temperature of the spray. The TVS model receives boundary condition of liquid hydrogen pressure and temperature and ullage pressure from self-pressurization model. The GFSSP model results were then compared with the test data. A 50\% Fill Level case was modeled to simulate the self-pressurization and TVS pressure cycling test. 


\section{Mathematical Formulation and Computer Program}

GFSSP is a finite volume based network flow analysis program for analyzing thermo-fluid systems. A fluid network consists of boundary nodes, internal nodes and branches to represent fluid system. . Boundary and internal nodes are connected through branches in series or parallel arrangements. At boundary nodes, pressures and temperatures are specified. . Mass and energy conservation equations are solved in internal nodes. Flowrates are calculated in branches. A thermal system consists of solid and ambient nodes connected with conductors. A fluid and solid node is connected with a solid to fluid conductor to model conjugate heat transfer.

The mathematical closure is described in Table 1. GFSSP uses a pressure based scheme as pressure is computed from mass conservation equation. The mass and momentum conservation equations and thermodynamic equation of state are solved simultaneously by the Newton-Raphson method while energy conservation equations of fluid and solid are solved separately but implicitly coupled with the other equations stated above. Further details of the mathematical formulation and solution procedure are described in reference 2.

Table 1. Mathematical Closure

$\underline{\text { Unknown Variables }}$

1. Pressure

2. Flowrate

3. Fluid Temperature

4. Solid Temperature

5. Fluid Mass (Unsteady Flow)

\section{$\underline{\text { Available Equations to Solve }}$}

1. Mass Conservation Equation

2. Momentum Conservation Equation

3. Energy Conservation Equation of Fluid

4. Energy Conservation Equation of Solid

5. Thermodynamic Equation of State

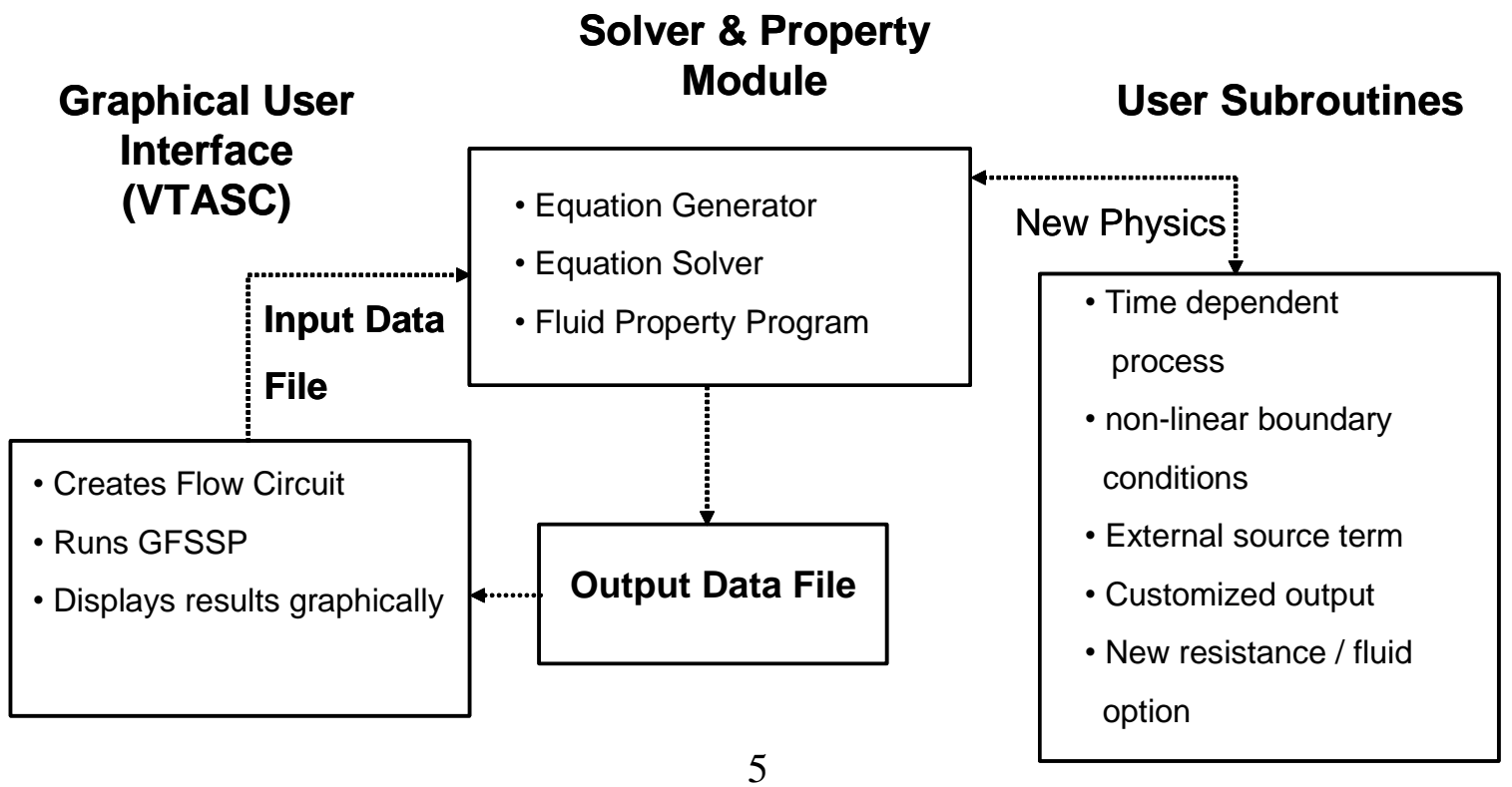


Figure 4. GFSSP's Program Structure showing the interaction of three major modules

Figure 4 describes the program structure of GFSSP. GFSSP has three major parts. The first part is the Graphical User Interface, VTASC (Visual Thermofluid Analyzer of Systems and Components). VTASC allows users to create a flow circuit by a 'point and click' paradigm. It creates the GFSSP input file after the completion of the model building process. It can also create a customized GFSSP executable by compiling and linking User Subroutines with the solver module of the code. Users can run GFSSP from VTASC and post process the results in the same environment. The second major part of the program is the Solver and Property Module. This is the heart of the program that reads the input data file, generates the required conservation equations for all internal nodes and branches with the help of thermodynamic property data. It also interfaces with User Subroutines to receive any specific inputs from users. Finally, it creates output files for VTASC to read and display results. The User Subroutine is the third major part of the program. This consists of several blank subroutines that are called by the Solver Module. These subroutines allow the users to incorporate any new physical model, resistance option, fluid etc. in the model.

\section{$\underline{\text { Solution Steps }}$}

Numerical modeling consists of following steps:

1. Subdivide the flow domain into fluid nodes and branches

2. Subdivide the solid domain into solid nodes and conductors

3. Connect the solid and fluid nodes with solid to fluid conductors

4. At each fluid node solve mass and energy conservation equation to calculate pressure and enthalpy of fluid and equation of state to compute resident mass of fluid

5. At each fluid branch, solve momentum conservation equations to calculate flow rate

6. From pressure and enthalpy, calculate fluid temperature and all other thermodynamic and thermo-physical properties required in governing equations

7. At each solid node, solve energy conservation equation to calculate temperature of the solid node

8. Steps 4 through 7 are repeated until convergence

9. Steps 4 through 8 are repeated for each time step

10. Terminate the calculation when final time step is reached

\section{GFSSP Model}

The primary intent of this effort was to develop an integrated multi-node model of ullage to simulate self-pressurization and pressure control by thermodynamic vent system. Two separate models for self-pressurization and TVS were developed and then the models were integrated. 


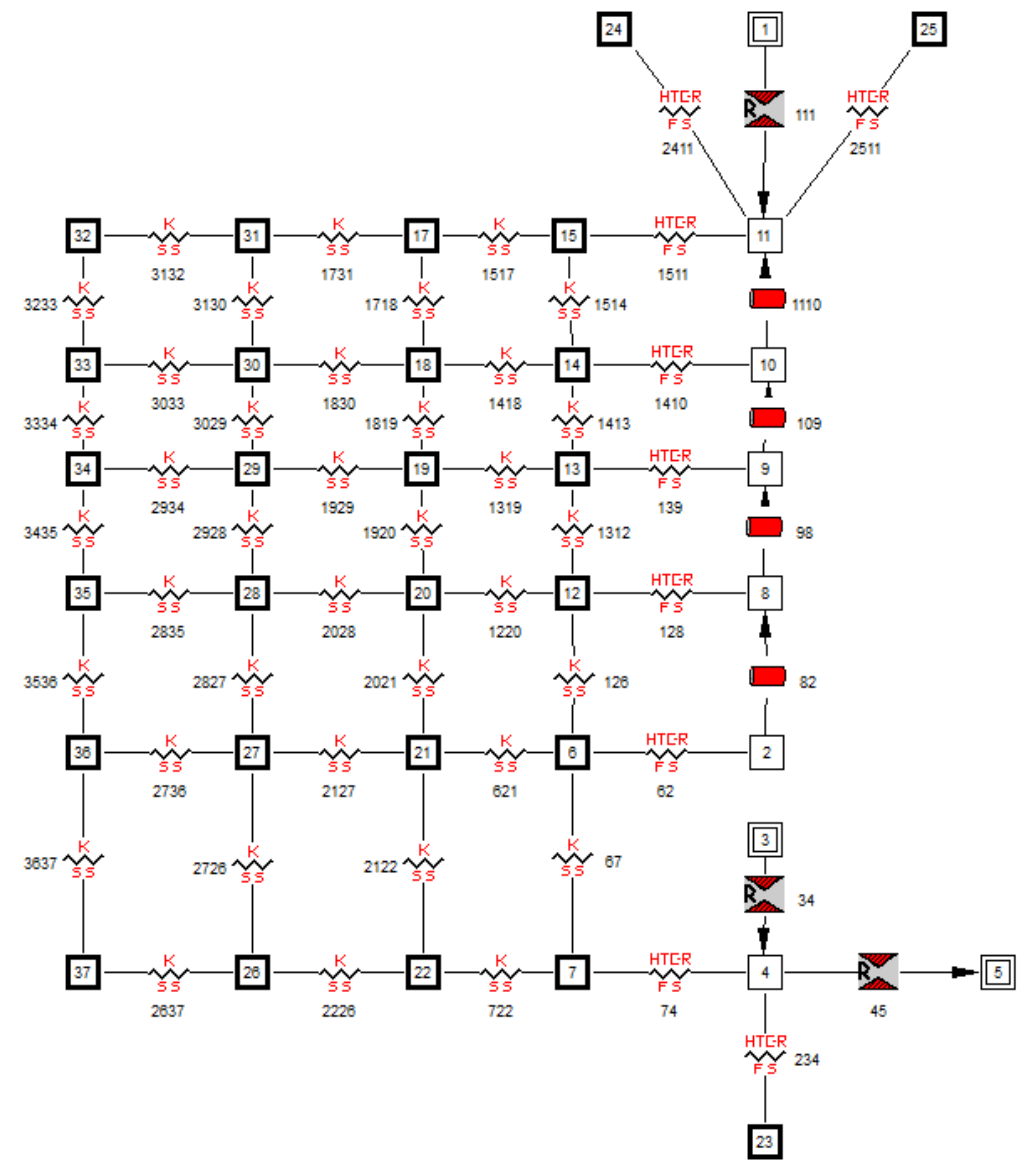

Figure 5. GFSSP Model of Self-Pressurization of MHTB Tank

Figure 5 shows the GFSSP model of self-pressurization in the MHTB Tank at the $50 \%$ fill level. Node 4 represents liquid hydrogen; Nodes 2, 8, 9, 10, and 11 represent the ullage at different fill levels. Node 3 is a pseudo-boundary node separating liquid hydrogen from vapor hydrogen in the ullage space. Each fluid node is connected with a solid node through a solidfluid conductor. There are four layers of solid node representing aluminum wall and SOFI insulation. For example, nodes 7 and 22 represent aluminum wall while nodes 26 and 37 represent SOFI insulation. Multi-Layer Insulation (MLI) was wrapped around SOFI insulation. Modeling of heat leak through MLI was performed in GFSSP's User Subroutine and was applied in outer layer of SOFI nodes (solid nodes 32 through 37 ).

\section{Modeling of heat leak through MLI}

Heat Transfer thru MLI can be expressed by the Modified Lockheed Equation ${ }^{5}$ :

$q=\left[\frac{C_{s}\left(0.017+7.0 E-6 *\left(800.0-T_{\text {avg }}\right)+2.28 E-2 * \ln \left(T_{\text {avg }}\right)\right)\left(N^{*}\right)^{2.63}\left(T_{h}-T_{c}\right)}{N_{s}}+\frac{C_{r} \varepsilon\left(T_{h}^{4.67}-T_{c}^{4.67}\right)}{N_{s}}+\frac{C_{g} P\left(T_{h}^{0.52}-T_{c}^{0.52}\right)}{N_{s}}\right]$ 
The actual heat transfer, however, was calculated by introducing a Degradation Factor, $\mathrm{D}_{\mathrm{f}}$. The heat transfer rate thru MLI was expressed as:

$q_{M L I}=D_{f} q$

Where,

$$
\begin{aligned}
& \text { Constants } \\
& \mathrm{C}_{\mathrm{s}}=2.4 \mathrm{E}-4 \\
& \mathrm{C}_{\mathrm{r}}=4.944 \mathrm{E}-10 \\
& \mathrm{C}_{\mathrm{g}}=14600 .
\end{aligned}
$$

\section{Variables and units}

q heat flux through MLI, $\mathrm{W} / \mathrm{m}^{2}$

$\mathrm{T}_{\mathrm{h}}$ hot boundary temperature, $\mathrm{K}$

$\mathrm{T}_{\mathrm{c}} \quad$ cold boundary temperature, $\mathrm{K}$

$\mathrm{T}_{\text {avg }}$ average of hot and cold boundary temperatures, $\mathrm{K}$

$\mathrm{N}^{*}$ MLI layer density, layers/cm

$\mathrm{N}_{\mathrm{s}}$ number of MLI layers

$\varepsilon$ MLI layer emissivity, $\varepsilon=0.031$

$\mathrm{P}$ interstitial gas pressure, torr

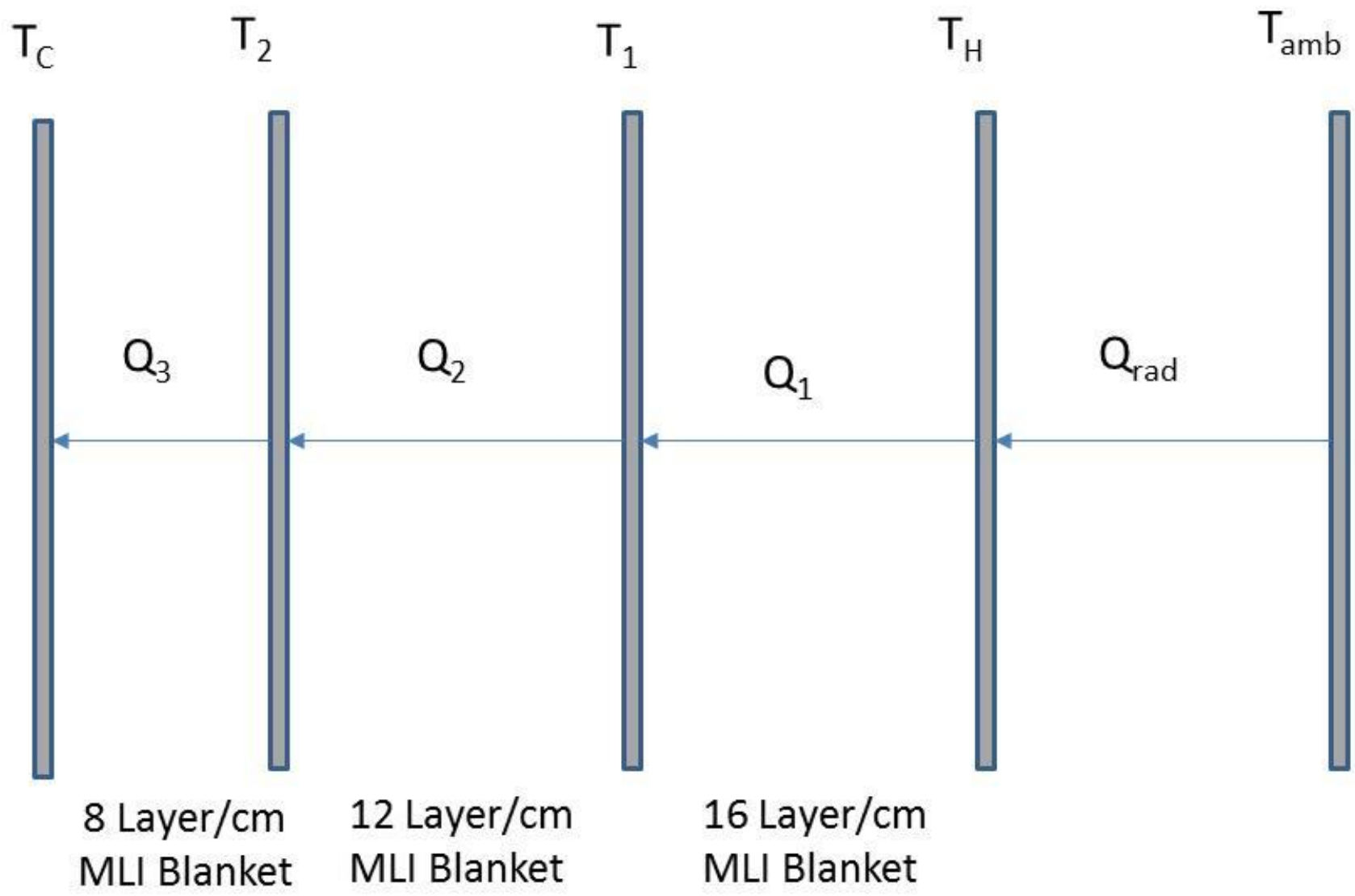

Figure 6. Multi-Layer Insulation Modeling Methodology 
Typically, several MLI blankets constitute MLI insulation. The mathematical modeling methodology is shown in Figure 6. According to the law of energy conservation:

$\mathrm{Q}_{\mathrm{rad}}=\mathrm{Q}_{1}=\mathrm{Q}_{2}=\mathrm{Q}_{3}$

where radiative heat transfer is given as:

$\mathrm{q}=\frac{\sigma\left(T_{a m b}^{4}-T_{o u t e r}^{4}\right)}{\frac{1}{\varepsilon_{M L I}}+\frac{1}{\varepsilon_{\text {shrd }}}-1}$

The law of energy conservation can also be expressed as:

$\mathrm{Q}_{2}\left(\mathrm{~T}_{1}, \mathrm{~T}_{2}\right)-\mathrm{Q}_{3}\left(\mathrm{~T}_{2}, \mathrm{~T}_{\mathrm{c}}\right)=0$

$\mathrm{Q}_{1}\left(\mathrm{~T}_{\mathrm{h}}, \mathrm{T}_{1}\right)-\mathrm{Q}_{2}\left(\mathrm{~T}_{1}, \mathrm{~T}_{2}\right)=0$

$Q_{\text {rad }}\left(T_{a m b}, T_{H}\right)-Q_{1}\left(T_{H}, T_{1}\right)$

These three equations [(5), (6), and (7)] are the governing equations to calculate temperature at the outer boundary $\left(\mathrm{T}_{\mathrm{H}}\right)$ and two intermediate temperatures $\left(\mathrm{T}_{1}\right.$ and $\left.\mathrm{T}_{2}\right)$ by the NewtonRaphson method. A subroutine MLI_HEAT_RATE was developed to solve these equations. Figure 6 shows the flowchart of MLI_HEAT_RATE subroutine which was called from Subroutine SORCETS. Subroutine SORCETS is called from the source code to provide any user specified heat source to a solid node.

MLI_HEAT_RATE Subroutine calls MLIEQNS, MLICOEF and GAUSSY to perform main computational tasks. MLIEQNS calculates residuals of the governing equations (Equations 5 through 7). Equations 1 and 2 are computed in QFLUXMLI and Equation 4 is computed in QFLUXRAD. The coefficients of the correction equation are computed in MLICOEF. The correction equations are solved in GAUSSY.

\section{$\underline{\text { Heat Transfer Coefficient Correlation }}$}

The heat transfer coefficient between wall and ullage was computed from a natural convection correlation for a vertical plate 6 . The set of equations used for this correlation is given below:

$N u=\left[\left(N u_{l}\right)^{m}+\left(N u_{t}\right)^{m}\right]^{1 / m} \quad \mathrm{~m}=6$

$N u_{t}=C_{t}^{V} R a^{1 / 3} /\left(1+1.4 \times 10^{9} \operatorname{Pr} / R a\right)$

$N u_{l}=\frac{2.0}{\ln \left(1+2.0 / N u^{T}\right)}$

$N u^{T}=\overline{C_{l}} R a^{1 / 4}$

$C_{t}^{V}=\frac{0.13 \operatorname{Pr}^{0.22}}{\left(1+0.61 \operatorname{Pr}^{0.81}\right)^{0.42}}$

where,

$G r=\frac{L^{3} \rho^{2} g \beta \Delta T}{\mu^{2}} ;=\frac{C_{p} \mu}{k} ; R a=G r P r$ and $N u=\frac{h L}{k}$. 


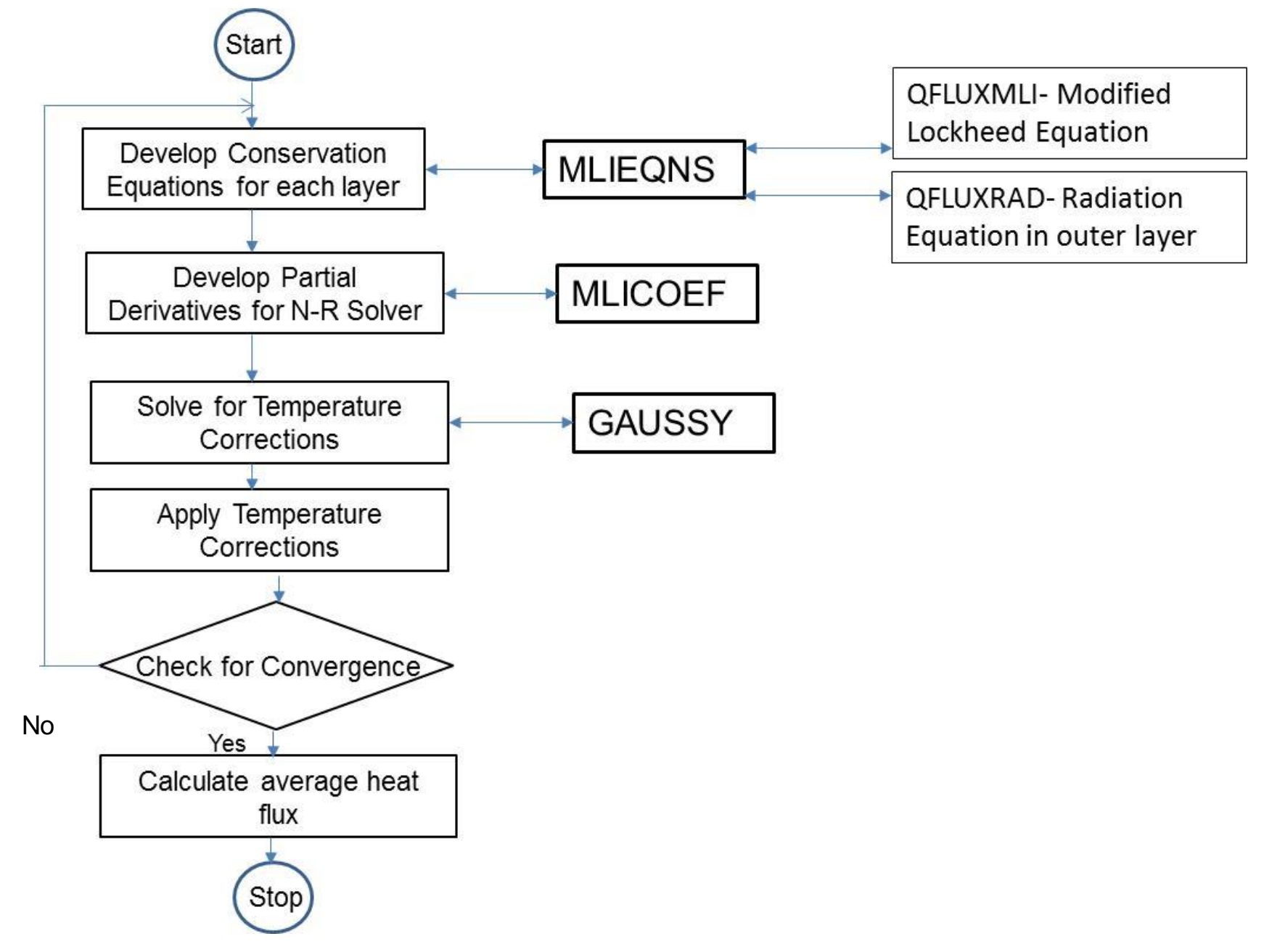

Figure 6. Flowchart of MLI_HEAT_RATE Subroutine

$\underline{\text { Liquid-Ullage Heat and Mass Transfer Model for Self-Pressurization }}$

Figure 7 shows the schematic of ullage and liquid propellant where there is a heat transfer between ullage to liquid propellant that also result into evaporative mass transfer.

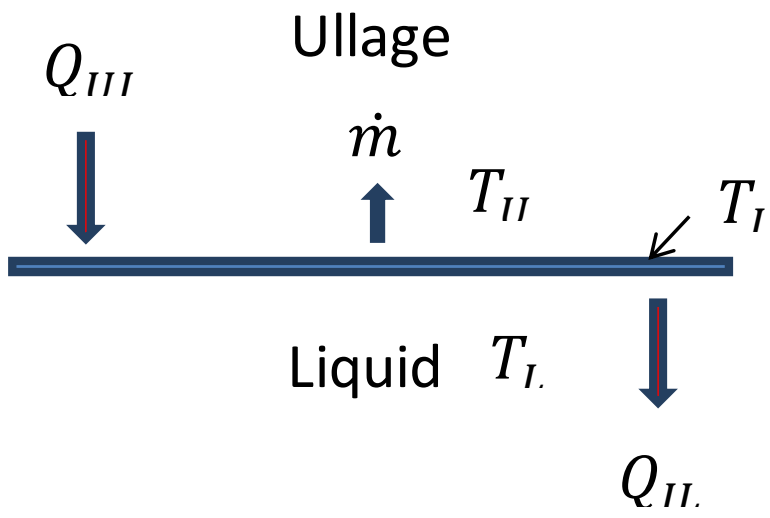


Figure 7. Evaporative Mass Transfer at Liquid-Vapor Interface

In this evaporative mass transfer model, a saturated layer is assumed at the interface between liquid and vapor. The saturated layer receives heat from the ullage $\left(\mathrm{Q}_{\mathrm{UI}}\right)$ and also rejects heat to the liquid $\left(\mathrm{Q}_{\mathrm{IL}}\right)$. The difference in this heat rate contributes to the mass transfer in accordance with the law of energy conservation. The equations governing this process are:

Heat Transfer from Ullage to Interface layer

$$
Q_{U I}=h_{U I} A\left(T_{U}-T_{I}\right)
$$

Heat Transfer from Interface to Liquid

$$
Q_{I L}=h_{I L} A\left(T_{I}-T_{L}\right)
$$

The evaporative mass transfer is expressed as:

$$
\dot{m}=\frac{Q_{U I}-Q_{I L}}{h_{f g}}
$$

The heat transfer coefficients $\mathrm{h}_{\mathrm{UI}}$ and $\mathrm{h}_{\mathrm{IL}}$ are computed from natural convection correlations given by:

$$
\begin{aligned}
\dot{m}=\frac{Q_{U I}-Q_{I L}}{h_{f, g}}, \\
h_{U I}=K_{H} C \frac{k_{f}}{L_{s}} R a^{n}=h_{I L}
\end{aligned}
$$

\section{$\underline{\text { TVS model }}$}

The purpose of the TVS model is to estimate the temperature and flowrate of the liquid hydrogen sprayed in the ullage to reduce the pressure and temperature. In TVS system, a small portion of liquid hydrogen is used for cooling the ullage. Before it is sprayed, it is further cooled in a heat exchanger where it is cooled by cold liquid-vapor mixture produced by a Joule-Thomson valve. 


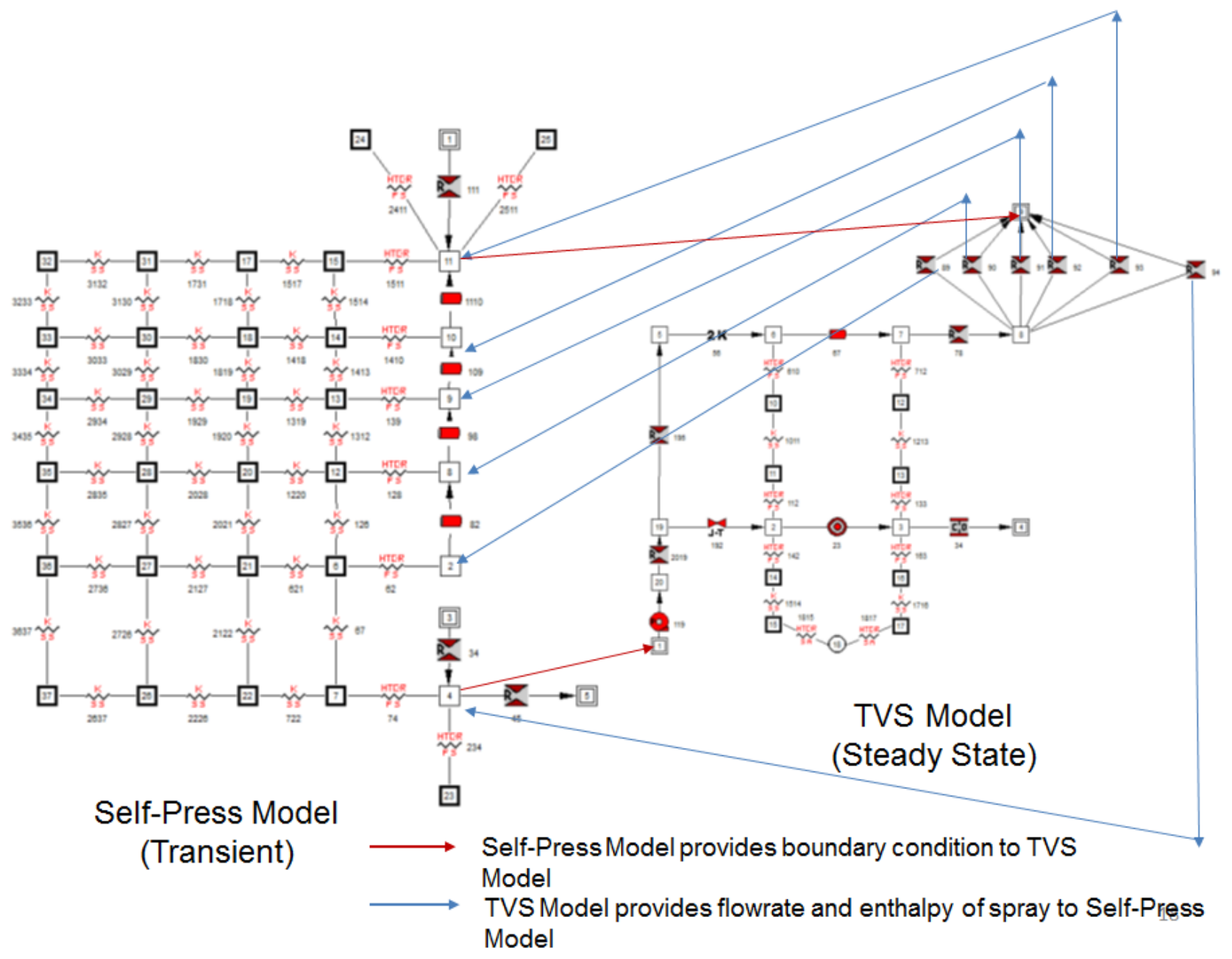

Figure 8. Integrated self-pressurization and TVS Model

The integrated model is shown in Figure 8 and integration of two models are done through exchange of boundary conditions by writing and reading model output data from files generated while model is running. The Self-Press model on the left is the driver model. When ullage pressure reaches the maximum allowable pressure, it makes a call to run the TVS model shown in the left. The details of the integration process is shown in Figure 9.

\section{Results}

This section presents the results of the combined GFSSP models of the MHTB. The transient self-pressurization model calls the steady-state model of the thermal vent system whenever the TVS is operating to reduce the pressure from 20 to 19 psia. 
Activate Spray when ullage pressure reaches upper bound

Write Pressure and temperature of liquid and ullage node in a specified file

\section{Run TVS model \\ "CALL SYSTEM('TVS.EXE TVS.DAT')" \\ TVS Model reads $P$ \& T of Boundary Nodes \\ \& writes Spray Mass Flowrate \& Enthalpy}

After return from TVS model, Self-

Press model reads Spray Data of

TVS Model

\section{Mass and Energy Sources are} introduced in ullage and liquid nodes

Figure 9. The main steps of model integration

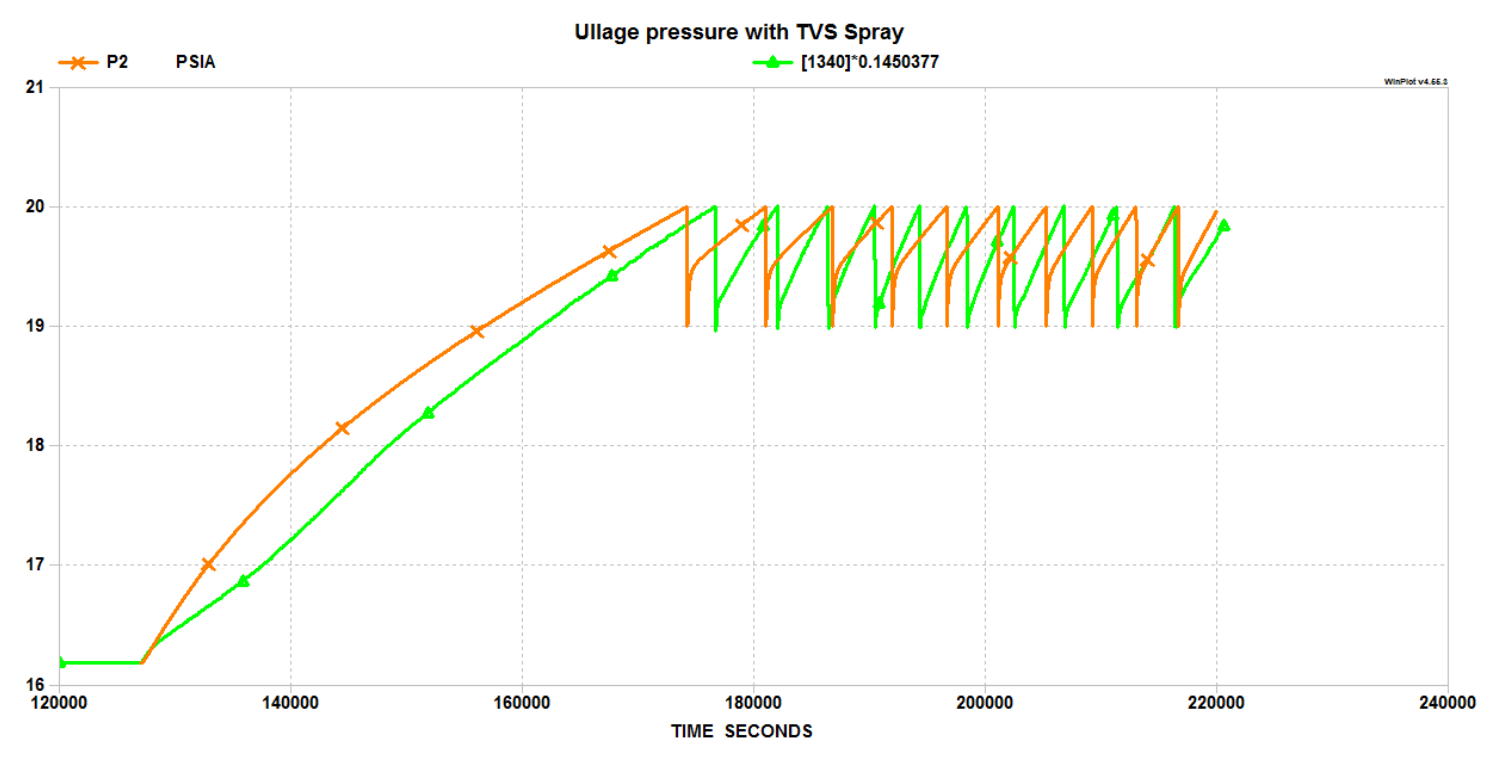

Figure 10: Measured (Green) and Predicted (Orange) Ullage Pressure (psia) 
Figure 10 plots the MHTB measured and predicted ullage pressure over time. MLI degradation factor of 4.0 was assumed for this calculation. The several reasons for observed discrepancies include the uncertainties of heat and mass transfer coefficients at ullage-liquid interface.

Figure 11 presents the measured ullage temperature in comparison with the predicted temperature in node 9 of the GFSSP model. Node 9 approximates the location of the temperature sensing diode. There is good agreement in the temperature rise rate during self-pressurization. During TVS operation, the predicted temperature is higher than the test data. This discrepancy can be attributed to the uncertainties in prediction of flowrate and temperature of the spray.

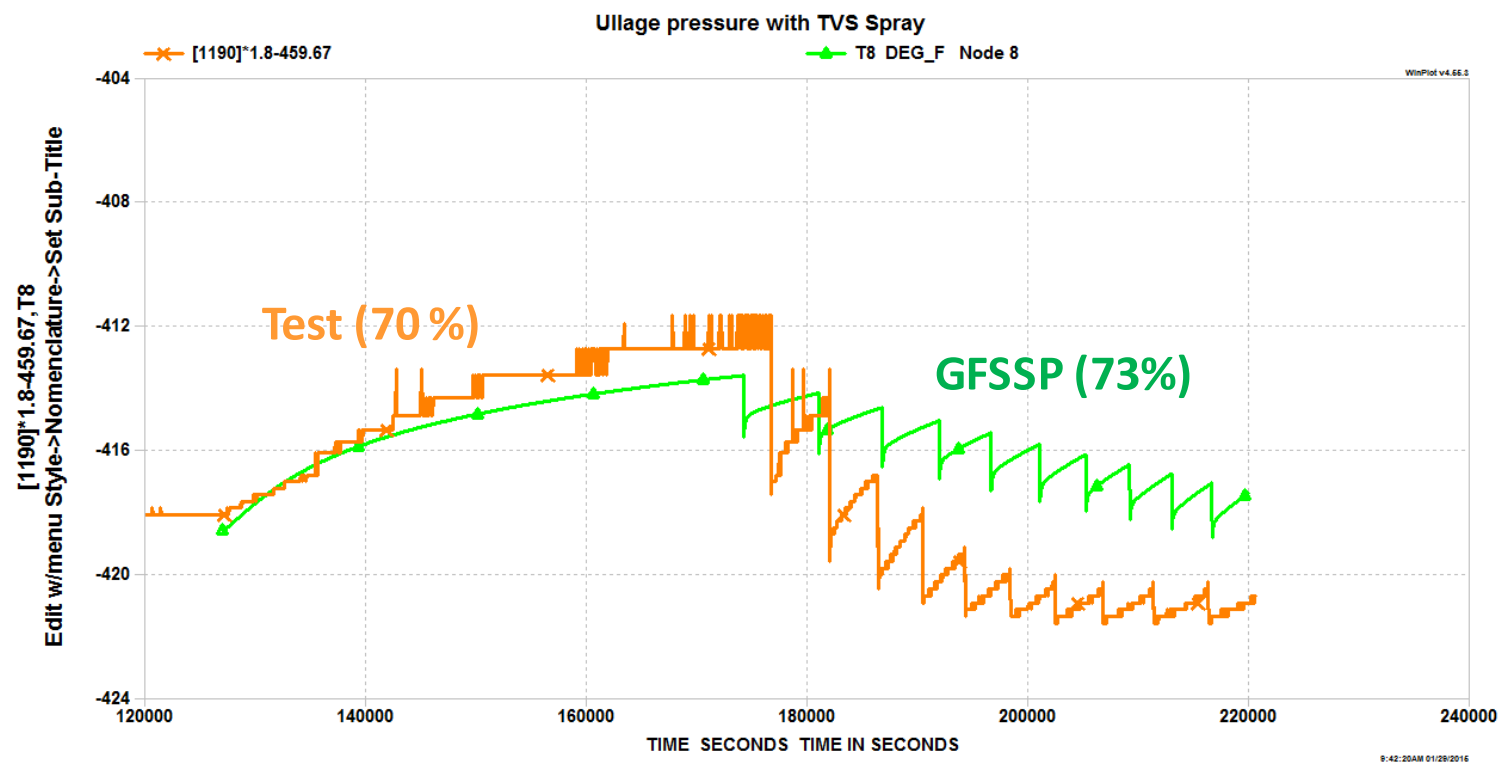

Figure 11: Measured (Orange) and Predicted (Green) Ullage Temperature $\left({ }^{\circ} \mathrm{F}\right)$ 


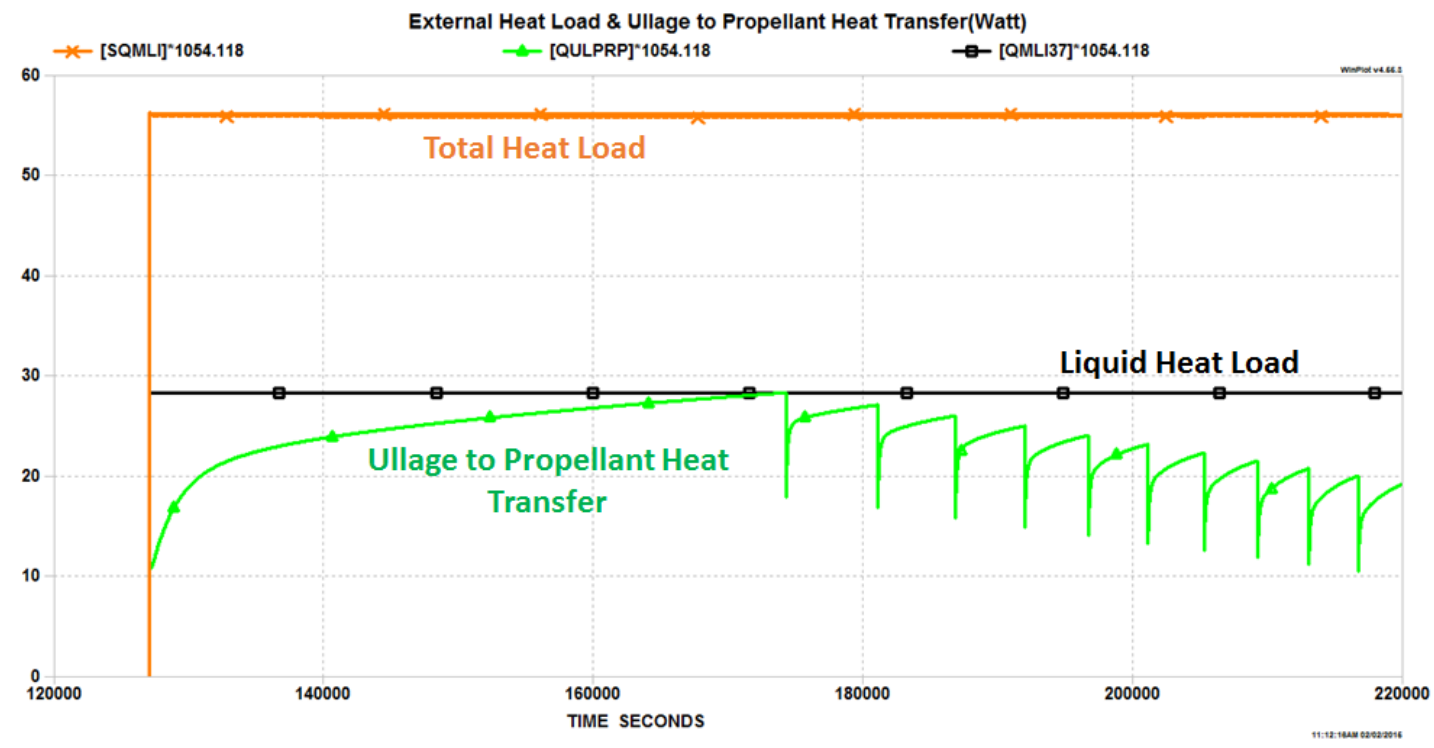

Figure 12: Predicted Heat Load and Ullage to Propellant Heat Transfer

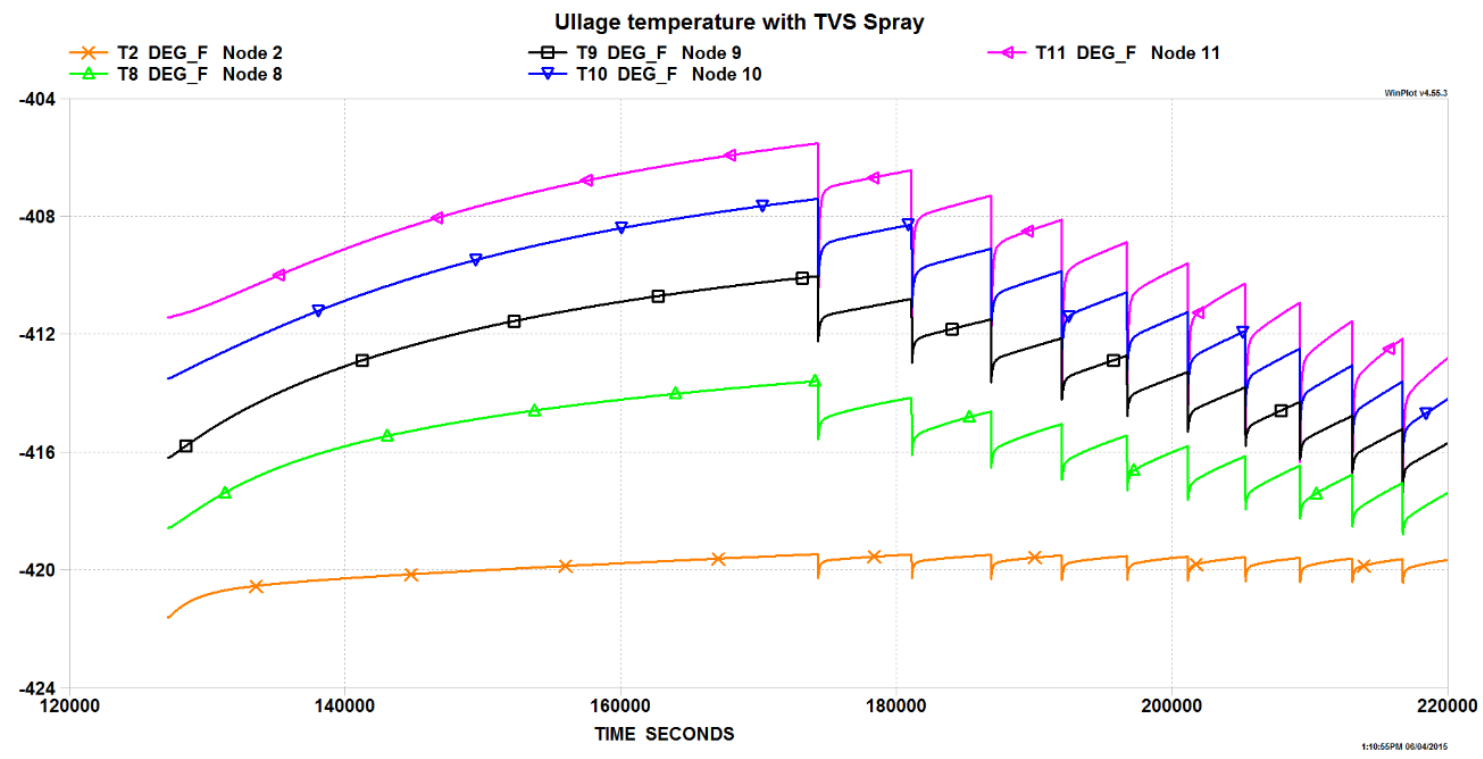

Figure 13: Predicted Ullage Temperature History

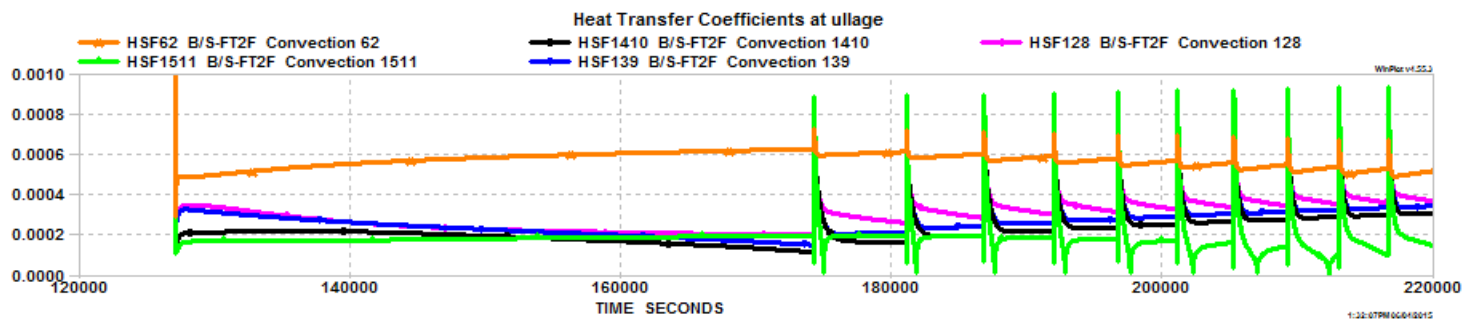

Figure 14: Predicted Heat Transfer Coefficients at five ullage nodes 


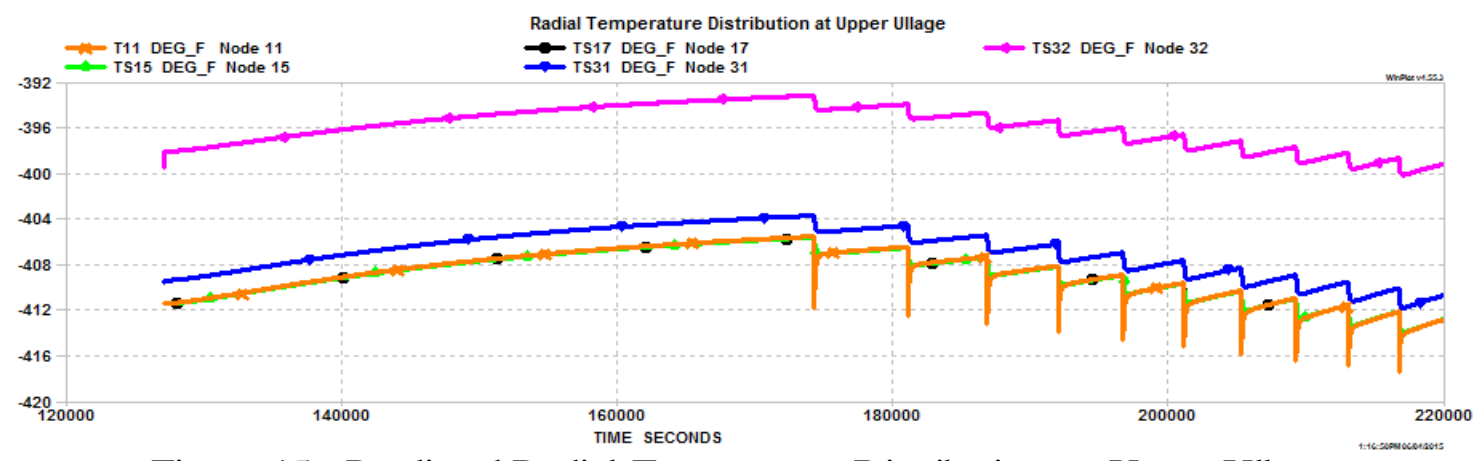

Figure 15: Predicted Radial Temperature Distribution at Upper Ullage

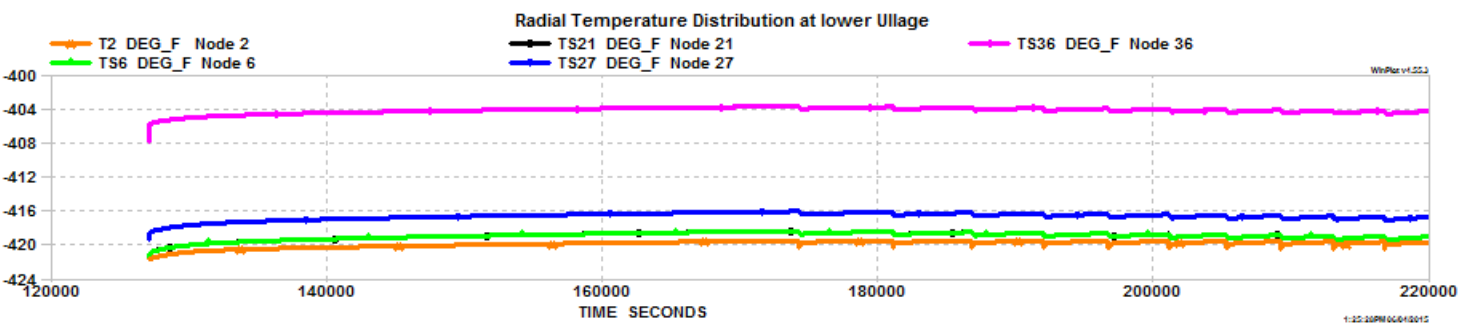

Figure 16: Predicted Radial Temperature Distribution at Lower Ullage

Figure 12 presents the predicted heat load and ullage to propellant heat transfer in watts. The predicted heat load matches closely with the test data reported in reference 3. It may be noted that heat load is evenly distributed between liquid and ullage for 50\% fill level. It is interesting to observe that ullage to liquid heat transfer is of comparable magnitude to heat leak into ullage or liquid.

Figure 13 presents the predicted ullage temperature history in all five nodes located in ullage space. The node 11 (pink) and node 2 (orange) are the highest and lowest node respectively. The drop in node temperature during TVS spray followed by rise due to selfpressurization is observed in the temperature profile. Higher the temperature, the larger is the drop during spray.

Figure 14 presents the predicted heat transfer coefficients at the interface between ullage node and solid node. The conductor "62" and "1511" represents the lowest and highest ullage node. The heat transfer coefficients are between 7 and $22 \mathrm{Btu} / \mathrm{hr}-\mathrm{ft}^{2}{ }^{\circ}{ }^{\circ} \mathrm{F}$. It is also observed that heat transfer coefficients are strong function of density. The highest heat transfer coefficients are observed near the liquid surface (orange) and lowest heat transfer coefficient occur at highest point (green).

Figure 15 and 16 present the radial temperature distribution at the upper and lower ullage respectively. It may be noted that plot does not include the temperature distribution in the MLI Layers. Evidently, the temperature drop through SOFI layer is much larger than metal wall. As noticed in Figure 13, the temperature spike due to spray is more pronounced in the upper ullage.

The Model took 8.05 hours to simulate 25.8 hours of real time test in a PC laptop (Intel, $2.6 \mathrm{GHz}$ ). The time step was $0.1 \mathrm{sec}$ for self-pressurization and 0.01 second during spray. 


\section{Conclusions}

A multi-node model of self-pressurization of a cryogenic tank in ground operation has been developed using GFSSP and compared with test data. The model calculates the heat transfer through multi-layer insulation, SOFI insulation and metal wall into ullage space and liquid propellant. Heat transfer through multi-layer insulation and vacuumed space between tank and shroud was calculated implicitly by solving modified Lockheed equation and radiative heat flux equation during the solution of energy conservation equation of solid nodes. It also calculates heat and mass transfer between ullage and liquid propellant. The self-pressurization model also includes the effect of liquid spray to cool the ullage and reduce the pressure. A thermodynamic vent system model was integrated with the selfpressurization model to provide the boundary condition of spray. The prediction of pressure cycling of integrated model matches satisfactorily with the test data.

\section{Acknowle dgement}

The authors wish to acknowledge the e-CRYO program of NASA/GRC for supporting this analytical task.

\section{References}

1. Martin, J.J.; and Hastings L.J.: "Large-Scale Liquid Hydrogen Testing of a Variable Density Multilayer Insulation With a Foam Substrate," NASA/TM-2001-211089, NASA Marshall Space Flight Center, Huntsville, AL, 88 pp., June 2001.

2. A.K. Majumdar, A.C. LeClair, R. Moore, P.A. Schallhorn, "Generalized Fluid System Simulation Program, Version 6.0", NASA/TM-2013-217492, October 2013. https://gfssp.msfc.nasa.gov/pdf/NASA_TM_2013_217492.pdf

3. Hastings, L.J.; Flachbart, R.H.; Martin, J.J.; et al.: "Spray Bar Zero-Gravity Vent System for On-Orbit Liquid Hydrogen Storage," NASA/TM-2003-212926, NAS A Marshall Space Flight Center, Huntsville, AL, 160 pp., October 2003.

4. Bolshinskiy, L; Hastings, L.J; Hedayat, A; et al.: "Tank System Integrated Model TankSIM Version 5.0,”ESSA_FY13-01202, May 2013.

5. Hastings, L. J., Hedayat, A., and Brown, T. M., Analytical Modeling and Test Correlation of Variable Density Multilayer Insulation for Cryogenic Storage, NASA/MSFC, NASA/TM-2004-213175, May 2004.

6. Rohsenow, W.M.; Hartnett, J.P.; and Cho, Y.I.: Handbook of Heat Transfer, 3rd ed., pp. 4.13, McGraw-Hill, 1998. 